\title{
Evidence of Oxidative Stress in Relation to Feeding Type During Early Life in Premature Infants
}

\author{
JAMES K. FRIEL, BILL DIEHL-JONES, KEVIN A. COCKELL, AARON CHIU, RASHEDA RABANNI, SEAN S. DAVIES,
} AND L. JACKSON ROBERTS II

\begin{abstract}
Department of Human Nutritional Sciences [J.K.F.], Faculty of Nursing [B.D.-J.], University of Manitoba, Winnipeg, Manitoba R3T 2N2, Canada; Department of Pediatrics [A.C., J.K.F.], University of Manitoba, Winnipeg, Manitoba R3E OW3, Canada; Nutrition Research Division [K.A.C.], Health Canada, Ottawa, Ontario K1A 0K9, Canada; Manitoba Institute of Child Health [R.R.], Winnipeg, Manitoba R3E 3P4, Canada; Department of Pharmacology [S.S.D., L.J.R.], Vanderbilt University, Nashville, TN 37232
\end{abstract}

\begin{abstract}
Morbidity in the premature (PT) infant may reflect difficult adaptation to oxygen. We hypothesized that feeding including formula feeding (F) and feeding mother's milk (HM) with added fortifier would affect redox status. Therefore, 65 PT infants (birth weight: $1146 \pm 261 \mathrm{~g}$; GA: $29 \pm 2.5 \mathrm{wk}$; mean \pm SD) were followed biweekly, once oral feeds were introduced. Feeding groups: F ( $>75 \%$ total feeds) and HM ( $>75 \%$ total feeds) were further subdivided according to human milk fortifier (HMF) content of $0-19,20-49$, and $\geq 50 \%$. Oxidative stress was quantified by F2-isoprostanes (F2-IsoPs) in urine, protein carbonyls, and oxygen radical absorbance capacity (ORAC) in plasma. F2IsoPs (ng/mg creatinine): 0-2 wk, $125 \pm 63$; 3-4 wk, $191 \pm 171$; 5-6 wk, $172 \pm 83 ; 7-8 \mathrm{wk}, 211 \pm 149 ; 9-10 \mathrm{wk}, 222 \pm 121$; and $>10 \mathrm{wk}, 183 \pm 67$. Protein carbonyls from highest $[2.41 \pm 0.75$ $(n=9)]$ and lowest [2.25 $\pm 0.89(n=12) \mathrm{pmol} / \mu \mathrm{g}$ protein] isoprostane groups did not differ. ORAC: baseline, $6778 \pm 1093$; discharge, $6639 \pm 735$ [full term 4 and $12 \mathrm{M}, 9010 \pm 600 \mathrm{mg}$ $(n=12)$ TE]. Highest isoprostane values occurred in infants with $>50 \%$ of their mother's milk fortified. Further research on HMF is warranted. (Pediatr Res 69: 160-164, 2011)
\end{abstract}

$\mathrm{E}$ levated concentrations of reactive oxygen species (ROS) have long been implicated as causal factors in human illness $(1,2)$. Although a number of enzymatic and nonenzymatic antioxidant defense mechanisms normally maintain an "uneasy truce" between oxidants and reductants, an imbalance can perturb homeostasis and result in disease. Nowhere is this perhaps more an issue than for the newborn infant. Birth itself may be viewed as a hyperoxic challenge, wherein the fetus transitions from a relatively hypoxic environment with a arterial oxygen tension of $25-35 \mathrm{~mm} \mathrm{Hg}$ (3) to the extrauterine environment where arterial oxygen tension reaches 100 $\mathrm{mm} \mathrm{Hg}$. Coupled with the oxidative stress induced through labor and higher-than-adult levels of mitochondrial respiration and peroxide production (4), the neonate may rely on compensatory mechanisms to transition successfully through the postpartum period such as ROS scavenging ability provided by human milk (5).

Received April 8, 2010; accepted September 23, 2010.

Correspondence: James K. Friel, Ph.D., Department of Human Nutritional Sciences, University of Manitoba, 190 Dysart Road, Room 511 Duff Roblin Bldg, Winnipeg, Manitoba R3T 2N2, Canada; e-mail: frielj@ms.umanitoba.ca

Supported from Canadian Institutes of Health Research operating Grant MOP 74463 and the Manitoba Institute of Child Health.
Previously, we showed that healthy breast-fed infants are under acute oxidative stress in early infancy reflecting the difficulty in adapting to increased oxygen exposure after birth (5). The challenge seems to be even more acute for the premature (PT) infant, for whom the normal developmental expression of antioxidant systems is either incomplete or compromised $(6,7)$ and who is often subjected to oxygen therapy and/or feeding strategies that contribute to redox imbalance $(8-10)$. Accordingly, oxidative stress is proposed to be either causal or at least strongly linked to a number of neonatal disorders, including bronchopulmonary dysplasia (BPD), periventricular leukomalacia, retinopathy of prematurity, intraventricular hemorrhage (IVH), and necrotizing eneterocolitis (NEC) (11-14).

What is clear is that a certain amount of oxidative stress is necessary to activate specific enzymatic pathways and that ROS act as signaling molecules. The PT infant would be expected to have a more difficult time at birth in the transition from fetal to neonatal life (2).

The extent of the challenge posed by free radicals and ROS for the preterm infant is becoming increasingly evident. Two plasma markers of lipid peroxidation, F2-isoprostanes (F2-IsoPs) and malonaldehyde, are elevated in very LBW infants with cerebral white matter injury, the latter $>10$-fold compared with adult controls (15). The significance of such findings is highlighted by the fact that preterm white matter is selectively vulnerable to oxidative damage (12). More recently, plasma F2-IsoPs have been shown to be elevated in children who were born preterm (16). The perinatal period may be a time of both increased exposure to and risk from oxidative stress. We have found that human milk in vitro acts as a better free radical scavenger than does infant formula (5).

We hypothesized that PT infants who were breast-fed would show less evidence of oxidative stress after birth than those who were formula fed. In this report, we present preliminary evidence that dietary factors may contribute to the overall level of oxidative stress in preterm infants. 


\section{MATERIALS AND METHODS}

Subjects. Sixty-five infants with birth weights $<1500 \mathrm{~g}$ were recruited from the Health Sciences Center and St. Boniface Research Center, Winnipeg, Manitoba, Canada, after birth but before oral feeds. Eligibility criteria included the following: prematurity $(<37 \mathrm{wk}$ GA by date of last menstrual period or early ultrasound) and birth weight $<1500$ g. Exclusion criteria included the following: presence of any major congenital anomaly, underlying genetic syndrome, presence of clinical or confirmed diagnosis of congenital infections, or unlikely to comply with necessary follow-up (i.e. out-of-province patients). Ethical approval was obtained from the University of Manitoba Research Ethics Board, and informed consent was obtained from all participants. For feeding purposes, the breast milk group was defined a priori as having received no $<75 \%$ of all oral feeds during their entire hospital stay as mother's own milk. The formula-feeding group was defined as having received no $<75 \%$ of all feedings in hospital from humanized infant formulas. The mixed-feeding group was defined as anything in between these two criteria. Given the variable intake of human milk fortifier (HMF) received during hospitalization, the breast milk group was further subdivided according to the total amount of breast milk fortified with HMF: $\geq 50,20-49$, and $0-19 \%$.

Sample collection. At study entry and biweekly thereafter, a blood sample was collected by venipuncture or from a catheter inserted centrally. Whole blood $(0.5-0.7 \mathrm{~mL})$ was collected in heparinized microtainers. Plasma was separated, and red blood cells were washed three times in saline before freezing at $-80^{\circ} \mathrm{C}$ until analysis. Urine samples were collected with a Hollister U-Bag (17), and after aliquoting to $1.5 \mathrm{~mL}$, clear plastic tubes were frozen at $-80^{\circ} \mathrm{C}$.

Data recorded from hospital records included the following: Apgar scores, SNAP scores (both severity of illness indices), duration and volume of parenteral nutrition, fortification with HMF (Mead Johnson Nutritionals, Evansville, IN); weight gain; incidence of oxygen exposure at both $28 \mathrm{~d}$ and 36 wk postconceptional age was recorded for defining BPD; days of ventilatory support; the worst grade of IVH including periventricular leukomalacia; incidence with none or either suspected or confirmed NEC (perforation and not perforated), using radiography; retinopathy of prematurity not present or identified as stage 1 or greater; cranial ultrasonography for IVH-PVH (d 7 and $\sim 36 \mathrm{wk}$ ); infections; not present or present with blood culture-proven sepsis (bacterial or fungal); cerebrospinal fluid culture proven meningitis; and urine positive result: presumed but not culture-proven sepsis.

F2-IsoPs a marker of lipid peroxidation in urine are prostaglandin-like compounds formed during peroxidation of arachidonic acid (18). The precision of the mass spectrometry assay is $\pm 5 \%$ with $80 \%$ accuracy. Normal adult levels in urine are $38.1 \pm 19.1 \mathrm{ng} / \mathrm{mg}$ creatinine (18). Creatinine was measured by standard techniques (18). Measurement of this compound in urine has the advantage that there is less likely to be autoxidation of samples when compared with blood analysis (18).

Antioxidant activity of plasma samples at the beginning and end of the study and mother's milk collected every $2 \mathrm{wk}$ was measured using the oxygen radical absorbance capacity (ORAC) according to procedures described by Prior et al. (19). An FLx800 micro plate fluorescence reader (Bio-Tek Instruments, Inc., Winooski, VT) was used with fluorescence filters for an excitation wavelength of $485 / 20 \mathrm{~nm}$ and an emission wavelength of $528 / 20 \mathrm{~nm}$. The plate reader was controlled by KC4 3.0 software (version 29). Dilution of sample, control, and Trolox standard was done manually. The quantity of $300 \mu \mathrm{L}$ each of buffer solution (blank) and diluted sample solution, control, and Trolox standard was transferred to a 96-well flat-bottom polystyrene micro plate (Corning Incorporated, Corning, NY) by hand according to their designated positions. A full automation of plate-to-plate liquid transfer was programmed by using a Precision 2000 micro plate pipetting system (Bio-Tek Instruments, Inc.). Peroxyl radical was generated by AAPH (2,2'-azobis-2-methyl-propanimidamide, dihydrochloride) during measurement, and fluorescein was used as the substrate. All the reaction mixtures were prepared in the measured plate in duplicate, and at least three independent assays were performed for each sample. Final ORAC values were calculated by using a regression equation between the Trolox concentration and the net area under the fluorescence decay curve. Area under the curve (AUC) was calculated as follows:

$$
\mathrm{AUC}=0.5+f_{1} / f_{0}+\ldots f_{i} / f_{0}+\ldots+f_{49} / f_{0}+0.5\left(f_{50} / f_{0}\right)
$$

where $f_{0}$ is the initial fluorescence reading at $0 \mathrm{~min}$ and $f_{i}$ is the fluorescence reading at time in min. The net AUC was obtained by subtracting the AUC of the blank from that of the sample. ORAC values were expressed as Trolox equivalents by using the standard curve. Final results were calculated and expressed as TE ( $\mu \mathrm{mol}$ Trolox equivalents) of plasma samples.

Antioxidant enzymes in red blood cells including superoxide dismutase, catalase, and glutathione peroxidase were analyzed as reported previously (5). Protein carbonyls were measured in plasma by a dot-blot immunoassay, following dinitrophenyl hydrazine reaction of protein carbonyl groups, using commercially available primary antibody to the resulting dinitrophenyl (DNP) derivatives [primary rabbit anti-DNP and horseradish peroxidase (HRP)conjugated secondary goat anti-rabbit], followed by ECL + and chemiluminescence detection (20). Plasma samples used for analysis of protein carbonyls were selected from those infants whose urine had the highest and lowest urinary isoprostane values to determine whether carbonyl content reflected isoprostane values and if further analysis should be done on the entire urine sample collection. Normal plasma protein carbonyl levels in appropriate-for-GA newborns have been reported as $1.31 \pm 0.24$ $\mathrm{pmol} / \mu \mathrm{g}$ protein (21).

Data analysis. Data for continuous variables were analyzed using univariate and multivariate repeated measures ANOVA procedures [SAS 9.1 (SAS Institute, Inc., Cary, NC) and SPSS 16.0 (SPSS, Inc, Chicago, IL)]. Log transformations were done for variables, which were not Gaussian. Significance was assigned to $p \leq 0.05$.

\section{RESULTS}

Subject characteristics are presented in Table 1. Plasma ORAC and red blood cell enzyme values are presented in Table 2; no significant differences were found over time. Subject clinical characteristics are presented in Table 3. F2IsoPs values were as follows: $0-2 \mathrm{wk}, 125 \pm 63 ; 3-4 \mathrm{wk}$, $191 \pm 171$; 5-6 wk, $172 \pm 83$; 7-8 wk, $211 \pm 149$; 9-10 wk, $222 \pm 121$; and $>10 \mathrm{wk}, 183 \pm 67$ ( $\mathrm{ng} / \mathrm{mg}$ creatinine). Normal levels from 40 adults: $38.1 \pm 19.1 \mathrm{ng} / \mathrm{mg}$ creatinine (18). Protein carbonyls from those subjects whose urine had the highest and lowest isoprostane values were as follows: high group: $2.41 \pm 0.75(n=9) \mathrm{pmol} / \mu \mathrm{g}$ protein; low group: $2.25 \pm 0.89(n=12) \mathrm{pmol} / \mu \mathrm{g}$ protein (mean $\pm \mathrm{SD} ; p=0.33$, not significant). Plasma ORAC: baseline, $6778 \pm 1093$; discharge, $6639 \pm 735$; [healthy PT 6 mo, $8134 \pm 706(n=7)$; full term 4 and $12 \mathrm{mo}, 9010 \pm 600 \mathrm{mg}(n=12)$; and adult $9295 \pm 887(n=6) \mathrm{TE}]$.

Isoprostane values according to percentage of HMF in total feedings are presented in Fig. 1. F2-IsoPs in the $>50 \%$ group were significantly greater than the formula-fed group $(p=$ 0.002). F2-IsoPs did not correlate either in a univariate or multivariate model with either of enzyme assays, anthropometric measurements, total days of $\mathrm{O}_{2}$ intake, GA, Apgar scores, type of feed in previous pregnancies, morbidity, or plasma or feed ORAC values. F2-IsoPs were related to gender (females $>$ males) and whether or not the infant had surgery for a patent ductus arteriosus (higher for surgery than no surgery).

Table 1. Subject characteristics

\begin{tabular}{lc}
\hline \multicolumn{1}{c}{ Characteristic } & Value \\
\hline Subjects $(n)$ & 65 \\
Birth weight $(\mathrm{g})$ & $1146 \pm 261$ \\
GA (wk) & $29 \pm 2.5$ \\
Discharge weight $(\mathrm{g})$ & $2437 \pm 582$ \\
Discharge length $(\mathrm{cm})$ & $46.0 \pm 3.3$ \\
Discharge head circumference $(\mathrm{cm})$ & $32.9 \pm 2$ \\
Maternal age $(\mathrm{yr})$ & $29 \pm 6$ \\
APGAR score $(95 \% \mathrm{CI})$, mean $\pm \mathrm{SD}$ (range) & \\
1 min & $6 \pm 2.3(1-9)$ \\
5 min & $8 \pm 1.5(4-9)$ \\
Days on supplemental $\mathrm{O}_{2}$ & $18 \pm 25$ \\
Total hospital days & $58 \pm 28$ \\
Percent days on $\mathrm{O}_{2}$ & $27 \pm 28$ \\
\hline
\end{tabular}

Values are represented as mean $\pm \mathrm{SD}$, unless specified. 
Table 2. Blood characteristics

\begin{tabular}{|c|c|c|c|}
\hline \multirow[b]{2}{*}{ Characteristic } & \multicolumn{3}{|c|}{ Weeks } \\
\hline & $0-4$ & $5-8$ & $\geq 9$ \\
\hline Plasma ORAC (TE) & $6778 \pm 1093^{*}(N=36)$ & $6376 \pm 857(N=22)$ & $6639 \pm 735(N=11)$ \\
\hline Superoxide dismutase (U/mg protein) & $39 \pm 15(N=45)$ & $36 \pm 13(N=37)$ & $38 \pm 15(N=30)$ \\
\hline Glutathione peroxidase (mU/mg protein) & $6 \pm 1.5(N=53)$ & $5.7 \pm 1.1(N=41)$ & $5.7 \pm 1.5(N=33)$ \\
\hline Catalase (mU/mg protein) & $120 \pm 32(N=41)$ & $134 \pm 29(N=29)$ & $165 \pm 41(N=27)$ \\
\hline
\end{tabular}

*Values are represented as mean $\pm \mathrm{SD}$.

Table 3. Clinical characteristics

\begin{tabular}{lrc}
\hline \multirow{2}{*}{ Characteristic } & \multicolumn{2}{c}{ No of subjects } \\
\cline { 2 - 3 } & Yes & No \\
\hline Received high-frequency ventilation & 12 & 53 \\
Received inhaled NO & 3 & 62 \\
Received surfactant & 47 & 18 \\
Infections* & 19 & 46 \\
NEC $\dagger$ & 4 & 61 \\
Signs of retinopathy of & 13 & 52 \\
$\quad$ prematurity & & \\
Appropriate for GA & 52 & 13 \\
\hline
\end{tabular}

* Not present or present with blood culture-proven sepsis (bacterial or fungal); cerebrospinal fluid culture-proven meningitis; urine positive result: presumed but not culture-proven sepsis $(n=4)$.

$\dagger$ Incidence with none or either suspected or confirmed $(n=1)$ NEC (perforation and not perforated) using radiography.

$\ddagger$ Retinopathy of prematurity not present or identified as stage 1 or greater.

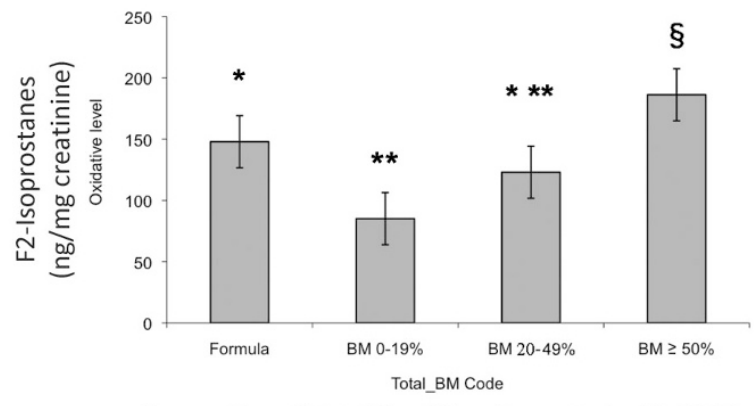

Proportion of Total Feed Supplemented with HMF

Figure 1. F2-IsoPs in urine by percentage of HMF fed over entire hospital stay, controlling for supplemental oxygen exposure, and gender. Normal adult level in urine $=38 \mathrm{ng} / \mathrm{mg}$ creatinine. $\log$ transformations were done for those variables, which were not Gaussian. Bars with different superscripts are significantly different at $p \leq 0.05$.

\section{DISCUSSION}

We found high levels of F2-IsoPs in urine during early infancy in the PT infant (Fig. 1) compared with normal adult levels of $\sim 38 \pm 19(n=40) \mathrm{ng} / \mathrm{mg}$ creatinine (18). These levels persisted to $>9 \mathrm{wk}$ after birth, reflecting the stress of prematurity. This was supported by our findings of nearly 2 -fold elevated protein carbonyl in the plasma of these infants compared with appropriate-weight-for-GA full-term newborns $[1.31 \pm 0.24 \mathrm{pmol} / \mu \mathrm{g}$ protein (21)]. Our results support those of other authors who assessed oxidative status in the PT infants (22-26). Farkouh et al. (22) reported elevated urinary peroxides in PT infants $(10 \mu \mathrm{mol} / \mathrm{mmol}$ creatinine $)$ compared with those of full-term infants $(5 \mu \mathrm{mol} / \mathrm{mmol}$ creatinine $)$ within the first $72 \mathrm{~h}$ of life. Cervantes-Munguia et al. (23) measured serum lipoperoxide levels in PT infants $<33 \mathrm{wk}$ gestation every week for the first month of life. Those infants who eventually developed retinopathy of prematurity (11/50) were more likely to have elevated lipoperoxides than those who did not develop the disease $(5.4 \pm 1.3 \mathrm{mmol} / \mathrm{mL}$ versus $2.9 \pm 0.9 \mathrm{mmol} / \mathrm{mL} p=0.0001)$. Similar results were found by Buonocore et al. (24) in both hypoxic and nonhypoxic PT infants with a normal clinical course at birth and $7 \mathrm{~d}$ later. Weinberger et al. (25) reported increasing levels of MDA, a lipid peroxidation product, in urine up to $10 \mathrm{~d}$ after birth in PT infants born $<30$ wk gestation. A recent report of F2-IsoPs in urine found no correlation with later outcome of BPD (26), whereas Ahola et al. (11) did find that plasma F2-IsoPs increased in PT infants who developed BPD. Metabolism of F2-IsoPs is likely different in urine and plasma and may explain the lack of consistency between studies.

Data from this study suggest that the PT infant is under considerable oxidative stress in early life. Elevated F2-IsoPs were also reported in children aged 8-13 y who had been born small-for-GA (16). In that study, compared with children born appropriate-for-GA, urinary isoprostanes were significantly elevated ( $46 \pm 4.6$ versus $29 \pm 3.1 \mathrm{ng} / \mathrm{mg}$ creatinine). These findings (16) were supported by increased erythrocyte oxidative products in small-for-GA $(287 \pm 17)$ versus appropriatefor-GA infants $(216 \pm 11 \mathrm{mmol} / \mathrm{g} \mathrm{Hb})$. It seems that early oxidative stress in PT infants may persist throughout childhood although other intervening variables may play a role. It is noteworthy that F2-IsoPs did not decline over the first 3 mo in these PT infants, whereas F2-IsoPs did decline over that time period in the full-term infant (5).

The measurement of F2-IsoPs has emerged as possibly the most reliable approach to assessing oxidative stress in vivo $(18,27)$. PT infants are known to have elevated metabolic rates compared with full-term infants and adults (4). Oxygen consumption is related to metabolic rate, which is dependent primarily on growth rate. As PT infants grow faster than term infants their metabolic rate will be higher (28). It is quite likely that the high levels of isoprostanes reflects this elevated metabolism and the possible weakened antioxidant defense mechanisms reported by others (6).

Plasma ORAC results (Table 2) suggest that the PT infant is somewhat compromised compared with full-term infants $(9010 \pm 600 \mathrm{TE})$ in early life. ORAC seems to rise over time as Franco et al. (16) found no difference in total antioxidant status between children who had been born PT or full term although there was greater evidence of oxidative stress in the children who had been born PT. These data are difficult to interpret and present a dilemma because a high value may 
mean increased ability to resist oxidative stress, whereas a low value may also mean that the infant is being protected. Prior et al. (19) have shown that ORAC is sensitive to dietary intake of antioxidants. However, a low ORAC value has not been linked to increased risk of disease. Furthermore, in this study, we did not find any relationship between ORAC and lipid peroxidation or any difference in peroxidation between infants who were breast-fed or formula fed. Subtle differences according to feeding may take longer to manifest even though breast milk and breast feeding have been shown to be protective to the PT infant (29-32). It should be mentioned that not all subjects were able to provide enough sample for all analyses, which may have affected our final results.

Previously, we reported that human milk was a better scavenger of free radicals than was infant formula (5). We tested a variety of PT formulas and mother's milk from PT infants and their relative ability to scavenge free radicals and inhibit lipid peroxidation. We found that mother's milk had a clear advantage even though known antioxidant molecules such as vitamins $\mathrm{C}$ and $\mathrm{E}$ are higher in PT formulas. Therefore, we expected to find lower levels of F2-IsoPs in the urine of breast-fed infants compared with that of formula fedinfants. Although this occurred for those infants who were fed primarily human milk without any supplements, an unexpected finding was the elevated urinary F2-IsoPs level in those infants who had their mother's milk fortified with HMF at the highest concentration (Fig. 1). HMF is widely used in neonatal units and was originally formulated to improve bone mineralization in PT infants (33). Why the group receiving the highest amounts of fortifier had the highest F2-IsoPs levels and higher than those fed only formula is unclear. The manufacturer's website (enfamil.ca) is clear that feeding should be prepared in a precise manner or there is risk of harm to the infant. In our experience, supplemental use in the neonatal unit shows wide variation with no consistent protocol (10). The known risk is that fortified human milk can spoil quickly and the consumption of oxidized lipids will increase the total body pool of oxidized lipids (34). Antibacterial activity of human milk was almost totally inhibited by the addition of bovine protein-based HMF (35). Other studies have shown that HMF sequesters endogenous milk anti-inflammatory cytokines (36). We have found that human milk with HMF allows bacterial growth within $1 \mathrm{~h}$ (unpublished). There is a paucity of information on the proper reconstitution and use of human breast milk substitutes (37). Typical errors include over- and under concentration, but there are persistent clinical questions as to the need for sterility, the safety and means of storage, and liquid versus powder formulations.

A recent Cochrane review (38) presents disturbing data but concludes that the "Use of a multicomponent fortifiers does not appear to be associated with adverse effects, although the total number of infants studied and the large amount of missing data reduces confidence in this conclusion." Currently, we are engaged in research using a cell culture model in an attempt to elucidate the possible mechanisms for generation of lipid peroxidation. Clearly, more work needs to be done.
Acknowledgments. We thank all parents who took part in this study. Sample collection was carried out by Cheryl Farrell, Maureen Pilz, Diana Schultz, and Lisa Merrill. Haifeng Yang, Gavin Broughton, Philip Griffin, and Apollo Tsopmo provided technical assistance.

\section{REFERENCES}

1. Boenig HV 1966 Free radicals and health: indicators for a unifying concept. J Am Geriatr Soc 14:1211-1220

2. Flora SJ 2007 Role of free radicals and antioxidants in health and disease. Cell Mol Biol (Noisy-le-grand) 53:1-2

3. Blackburn S 1992 Alterations of the respiratory system in the neonate: implications for clinical practice. J Perinat Neonatal Nurs 6:46-58

4. Singer D, Muhlfeld C 2007 Perinatal adaptation in mammals: The impact of metabolic rate. Comp Biochem Physiol A Mol Integr Physiol 148:780-784

5. Friel JK, Martin SM, Langdon M, Herzberg GR, Buettner GR 2002 Milk from mothers of both premature and full-term infants provides better antioxidant protection than does infant formula. Pediatr Res 51:612-618

6. Frank L, Bosanko IR 1987 Prenatal development of lung antioxidant enzymes in four species. J Pediatr 110:106-110

7. Asikainen TM, Raivio KO, Saksela M, Kinnula VL 1998 Expression and developmental profile of antioxidant enzymes in human lung and liver. Am J Respir Cell Mol Biol 19:942-949

8. Vento G, Mele MC, Mordente A, Romagnoli C, Matassa PG, Zecca E, Zappacosta B, Persichilli S 2000 High total antioxidant activity and uric acid in tracheobronchial aspirate fluid of preterm infants during oxidative stress: an adaptive response to hyperoxia? Acta Paediatr 89:336-342

9. Chess PR, D'Angio CT, Pryhuber GS, Maniscalco WM 2006 Pathogenesis of bronchopulmonary dysplasia. Semin Perinatol 30:171-178

10. Friel JK, Diehl-Jones WL, Suh M, Tsopmo A, Shirwadkar VP 2007 Impact of iron and vitamin C-containing supplements on preterm human milk: in vitro. Free Radic Biol Med 42:1591-1598

11. Ahola T, Fellman V, Kjellmer I, Raivio KO, Lapatto R 2004 Plasma 8-isoprostane is increased in preterm infants who develop bronchopulmonary dysplasia or periventricular leukomalacia. Pediatr Res 56:88-93

12. Back SA, Luo NL, Mallinson RA, O'Malley JP, Wallen LD, Frei B, Morrow JD, Petito CK, Roberts CT Jr, Murdoch GH, Montine TJ 2005 Selective vulnerability of preterm white matter to oxidative damage defined by F2-isoprostanes. Ann Neurol 58: $108-120$

13. Kermorvant-Duchemin E, Sennlaub F, Chemtob S, Behar-Cohen F 2006 [Pathophysiology of retinopathy of prematurity]. Arch Pediatr 13:566-568

14. Zhou Y, Wang Q, Mark Evers B, Chung DH 2006 Oxidative stress-induced intestinal epithelial cell apoptosis is mediated by p38 MAPK. Biochem Biophys Res Commun 350:860-865

15. Inder T, Mocatta T, Darlow B, Spencer C, Volpe JJ, Winterbourn C 2002 Elevated free radical products in the cerebrospinal fluid of VLBW infants with cerebral white matter injury. Pediatr Res 52:213-218

16. Franco MC, Kawamoto EM, Gorjao R, Rastelli VM, Curi R, Scavone C, Sawaya AL, Fortes ZB, Sesso R 2007 Biomarkers of oxidative stress and antioxidant status in children born small for gestational age: evidence of lipid peroxidation. Pediatr Res 62:204-208

17. Friel JK, Bessie JC, Belkhode SL, Edgecombe C, Steele-Rodway M, Downton G, Kwa PG, Aziz K 2001 Thiamine, riboflavin, pyridoxine, and vitamin C status in premature infants receiving parenteral and enteral nutrition. J Pediatr Gastroenterol Nutr 33:64-69

18. Davies SS, Zackert W, Luo Y, Cunningham CC, Frisard M, Roberts LJ II 2006 Quantification of dinor, dihydro metabolites of F2-isoprostanes in urine by liquid chromatography/tandem mass spectrometry. Anal Biochem 348:185-191

19. Prior RL, Gu L, Wu X, Jacob RA, Sotoudeh G, Kader AA, Cook RA 2007 Plasma antioxidant capacity changes following a meal as a measure of the ability of a food to alter in vivo antioxidant status. J Am Coll Nutr 26:170-181

20. Cockell KA, Wotherspoon AT, Belonje B, Fritz ME, Madere R, Hidiroglou N, Plouffe LJ, Ratnayake WM, Kubow S 2005 Limited effects of combined copper deficiency: iron overload on oxidative stress parameters in rat liver and plasma. J Nutr Biochem 16:750-756

21. Saker M, Mokhtari NS, Merzouk SA, Merzouk H, Belabor B, Nacre M 2008 Oxidant and antioxidant status in mothers and their newborns according to birthweight. Eur J Obstet Gynecol Reprod Biol 141:95-99

22. Farkouh CR, Merrill JD, Ballard PL, Ballard RA, Ischiropoulos H, Lorch SA 2006 Urinary metabolites of oxidative stress and nitric oxide in preterm and term infants. Biol Neonate 90:233-242

23. Cervantes-Munguía R, Espinosa-López L, Gómez-Contreras P, Hernández-Flores G, Domínguez-Rodríguez J, Bravo-Cuéllar A 2006 Retinopathy of prematurity and oxidative stress. An Pediatr (Barc) 64:126-131

24. Buonocore G, Perrone S, Longini M, Vezzosi P, Marzocchi B, Paffetti P, Bracci R 2002 Oxidative stress in preterm neonates at birth and on the seventh day of life. Pediatr Res 52:46-49

25. Weinberger B, Anwar M, Henien S, Sosnovsky A, Hiatt M, Jochnowitz N, Witz G, Hegyi T 2004 Association of lipid peroxidation with antenatal betamethasone and oxygen radial disorders in preterm infants. Biol Neonate 85:121-127

26. Reuter SD, O'Donovan DJ, Hegemier SE, Smith EO, Heird WC, Fernandes CJ 2007 Urinary F2-isoprostanes are poor prognostic indicators for the development of bronchopulmonary dysplasia. J Perinatol 27:303-306 
27. Fessel JP, Jackson Roberts L 2005 Isofurans: novel products of lipid peroxidation that define the occurrence of oxidant injury in settings of elevated oxygen tension. Antioxid Redox Signal 7:202-209

28. Chessex P, Reichman BL, Verellen GJ, Putet G, Smith JM, Heim T, Swyer PR 198 Relation between heart rate and energy expenditure in the newborn. Pediatr Res 15:1077-1082

29. Friel JK, Friesen RW, Harding SV, Roberts LJ 2004 Evidence of oxidative stress in full-term healthy infants. Pediatr Res 56:878-882

30. Aycicek A, Erel O, Kocyigit A, Selek S, Demirkol MR 2006 Breast milk provides better antioxidant power than does formula. Nutrition 22:616-619

31. Hylander MA, Strobino DM, Pezzullo JC, Dhanireddy R 2001 Association of human milk feedings with a reduction in retinopathy of prematurity among very low birthweight infants. J Perinatol 21:356-362

32. van Zoeren-Grobben D, Lindeman JH, Houdkamp E, Brand R, Schrijver J, Berge HM 1994 Postnatal changes in plasma chain-breaking antioxidants in healthy preterm infants fed formula and/or human milk. Am J Clin Nutr 60:900-906
33. Schanler RJ, Abrams SA 1995 Postnatal attainment of intrauterine macrominera accretion rates in low birth weight infants fed fortified human milk. J Pediat 126:441-447

34. Staprãns I, Rapp JH, Pan XM, Kim KY, Feingold KR 1994 Oxidized lipids in the diet are a source of oxidized lipid in chylomicrons of human serum. Arterioscler Thromb 14:1900-1905

35. Chan GM, Lee ML, Rechtman DJ 2007 Effects of a human milk-derived human milk fortifier on the antibacterial actions of human milk. Breastfeed Med 2:205-208

36. Jocson MA, Mason EO, Schanler RJ 1997 The effects of nutrient fortification and varying storage conditions on host defense properties of human milk. Pediatrics 100:240-243

37. Renfrew MJ, Ansell P, Macleod KL 2003 Formula feed preparation: helping reduce the risks; a systematic review. Arch Dis Child 88:855-858

38. Kuschel CA, Harding JE 2004 Multicomponent fortified human milk for promoting growth in preterm infants. Cochrane Database Syst Rev CD000343 